\title{
Creation features of the Drum Ballads about War and chivalrous and detective in the Qing Dynasty
}

\author{
Yang Yanru \\ Department of Literature and Journalism, Inner Mongolia University \\ *Correspondence: $1452437083 @ q q . c o m$
}

\begin{abstract}
The creation of the masters in the Qing Dynasty showed the collective wisdom of folk artists. The Mongolian Che Wangfu had a typical reputation for the "Qing Guan" and"Xia Ke" in the Qing Dynasty. It combines mythological stories, the hero's magical birth story, and their fascinating teaching in singing, which has some lyrics, reflecting the understanding of the fame, morality, and benefits in the Qing Dynasty.
\end{abstract}

Keywords: Qing Dynasty; Drum Ballads; Creation Characteristics.

\section{Introduction}

The academic community has enriched results in many significant cases, mainly focusing on the origin of such novels and their significance in the research. Drum Ballads is a particular style, and the combination of a form of said and sung. For instance, from Che Wangfu, the Drum Ballads is about "San Xia Wu Yi" "Peng Gong An". It has prose and verse format. Usually, it creates folk art people, which could help ordinary people understand the legal system. The creation of the masters of the Qing Dynasty has attracted more grassroots people, fully considering the people's curiosity ${ }^{[1]}$. In addition, the creative technique is different from the novel, and the specific characters are as follows.

\section{Shaping typical character}

In the Qing Dynasty, the criteria mainly created two pieces of literature, "Qing Guan" and "Xia Ke." "Qing Guan" refers to those who have a noble character, clean style, and justice. Everywhere in Chinese history, all officials are, the clerk is also the hero that often appears in Chinese literary works. During the Chinese Han Dynasty, there were many stories about detectives. In the Wei Dynasty, these stories are written in history books. But the content of the story has changed, and it is based on the richness of the plot. In Tang Legend, "Su Wu Ming" "Xie Xiao e" has a high historical value. In these works, the story of the case has gradually evolved into an independent form. From the Song Dynasty to the Qing Dynasty, the appreciation and recognition of the clerk can be seen in the written notes. On the other hand, the knight is also a kind of person worthy of attention ${ }^{[2]}$.

The shape of the "Xia Ke" image in the novel starts from the Chinese Han Dynasty. "Wu Yue Chunqiu" shaped the first
"Xia Ke" image in the history of Chinese chivalrous novels, "Yan Danzi" also recorded Jing Ke's story and praised Jing Ke's derogatory character and broad mind. Jing Ke is already a real hero. Combining the two typical images of the "Qing Guan" and "Xia Ke" can form a new literary genre, such as the Drum Ballads from Che Wangfu of the Qing Dynasty, one of the new works. This character is mainly shaping the typical characters and more tension. The cooperation of "Qing Guan" and "Xia Ke" can significantly improve the efficiency of the case, reflecting their incredible attention to the law. They are the hero in the mind of ordinary people. When the people read or appreciate them, they can understand the justice and courage of the heroes, which can inspire more people to worship the hero ${ }^{[3]}$.

\section{Imitation myth}

In the Qing Dynasty, the tyrants of the Qing Dynasty were shaping the Qingguan's image, not only giving them wisdom in the process of discharging the case and the manipulation but also giving them some mythological colours. Among them, the magical birth story of Bao Gong is even more eyecatching, which will make Baogong becomes a hero who is yearning to worship. Bao Gong's magical birth story in the emulsions in the Qing Dynasty, related to Chinese traditional magical born myths. The birth of the "Book of Songs" has also recorded the birth experience of the fellow, and their common point is that people have strange signs before birth, and special appearances, postures, languages will accompany them ${ }^{[4]}$. The growth process of people will not be smooth and will be abandoned, but the final result is shocking and delightful. 
In the Drum Ballads from Che Wangfu about "Bao Gong An" in the Qing Dynasty, the magical birth story of Bao Gong has a lot of similarities with the magical birth story in early mythology. For example, Bao Gong has a red light in front of the house. After Bao Gong is born, you can stand in one leg. There is a croissant on his head. The whole body is black, and it isn't pleasant. People are afraid that it will throw him to the foot of the mountain. Later, I found that A tiger saved bao, Gong. Finally, the family was hugged home and grew up smoothly. The storyline logic is clear; the narrative techniques and skills imitate ancient Chinese mythology ${ }^{[5]}$.

From the above story, you can learn that the story of Bao Gong is composed of a dream, magical birth, abandonment, and rescue, full of fantasy colours. Qing Dynasty's masters have made further descriptions of this fantasy colour, making the typography of particular significance.

\section{Lyrics}

The leading role of the masses in the Qing Dynasty, the most crucial part, is to teach the public. When the folk artist in the Qing Dynasty told the story, he could only grasp the audience's attention. He also consciously pleases the public. First, the Drum Ballads in the Qing Dynasty often expressed their good and malicious views good at subfunction of goodness and impartiality. Those drum artists who perform at the grassroots level tell "Xia" and "Dao" to say to people to abide by the legal system ${ }^{[4]}$. When they say that the knight walks the rivers and lakes, they deliberately explain that the rude personality of the knight will change with the help of the clerk. The knights return to the process of the government, and it is also a potential value orientation that typically ${ }^{[6]}$.

Secondly, the Drum Ballads in the Qing Dynasty reflected people's forwarding. For example, many sentences describe the scenery of the scene. Usually, the typical sentences express the people's peaceful social world straightforwardly. This kind of lyrical tendency is told about the singing artist in Shengshi. Moreover, it is the desire and pursuit of city wellknown martial arts represented by artists ${ }^{[1]}$.

\section{Conclusions and Prospects}

In summary, the Drum Ballads in the Qing Dynasty have three characteristics in the creation, including the two typical characters of the "Qingguan" and "Xia Ke," combined with the Chinese mythology, and finally created a hero's birth story. Such phosphors reflect some interesting and teaching and have a significant lyrical function, reflecting those singing artists have a deep understanding of justice and appreciation and expectations of a beautiful life. Qing Dynasty, the masters of the Qing Dynasty, the seamless concomitance of singing lyrics and listening to the psychological psychology, said that the seamless catering of lyrics and audience psychology is a new presentation of "Brookfield" performance. Under a particular Qing Dynasty society, the Drum Ballads in the Qing Dynasty have a specific aesthetic meaning, and it is a precious literary heritage in the ancient folk.

\section{References}

[1] Qing Mongolian Che Wangfu Tibetan "San Xia Wuyi" 17th, 18th, "Megang Case", 31st to 36th, "Peng Gong an" 41, 42 . Beijing: Xueyuan Publishing House, 2001.

[2] Li Xuemei, Yuhong, Huo Yaozhong, Yin Bianying: China's Experiment Literature Development History. Shanghai: Shanghai People's Publishing House, 2012.

[3] Meng Liye: History of Art Development of Chinese Cooperative Novels . Beijing: Police Officer Education Press, 1996.

[4] Miao Huaiming: History of ancient Chinese public case novels . Nanjing: Nanjing University Press, 2005.

[5] Chen Qi Tan: Han Ai Note . Shanghai: Shanghai Ancient Books Publishing House, 2000.

[6] Simaqian moved, Han Zhaoqi translated: History . Beijing: Zhonghua Book Company, 2007. 